\title{
Disease-Weather Relationships for Powdery Mildew and Yellow Rust on Winter Wheat
}

\author{
D. E. Te Beest, N. D. Paveley, M. W. Shaw, and F. van den Bosch
}

First and fourth authors: Biomathematics and Bioinformatics department, Rothamsted Research, Harpenden, Hertfordshire, AL5 2 JQ, UK; second author: ADAS High Mowthorpe, Duggleby, Malton, North Yorkshire, YO17 8BP, UK; and third author: School of Biological Sciences, University of Reading, Reading RG6 6AS, UK.

Accepted for publication 8 January 2008.

ABSTRACT

\begin{abstract}
Te Beest, D. E., Paveley, N. D., Shaw, M. W., van den Bosch, F. 2008. Disease-weather relationships for powdery mildew and yellow rust on winter wheat. Phytopathology 98:609-617.

Key weather factors determining the occurrence and severity of powdery mildew and yellow rust epidemics on winter wheat were identified. Empirical models were formulated to qualitatively predict a damaging epidemic ( $>5 \%$ severity) and quantitatively predict the disease severity given a damaging epidemic occurred. The disease data used was from field experiments at 12 locations in the UK covering the period from 1994 to 2002 with matching data from weather stations within a $5 \mathrm{~km}$ range. Wind in December to February was the most influential factor for
\end{abstract}

a damaging epidemic of powdery mildew. Disease severity was best identified by a model with temperature, humidity, and rain in April to June. For yellow rust, the temperature in February to June was the most influential factor for a damaging epidemic as well as for disease severity. The qualitative models identified favorable circumstances for damaging epidemics, but damaging epidemics did not always occur in such circumstances, probably due to other factors such as the availability of initial inoculum and cultivar resistance.

Additional keywords: Blumeria graminis f. sp. tritici, climate change, data mining, epidemiology, Puccinia striiformis.
Powdery mildew (Blumeria graminis f. sp. tritici Em. Marchal) and yellow rust (Puccinia striiformis Westend. f. sp. tritici) are damaging foliar diseases in winter wheat (Triticum aestivum). If an infection is untreated yield reduction as a result of powdery mildew or yellow rust infection can typically be around 10 to $20 \%$ and sometimes up to $40 \%$ (32). Powdery mildew occurs on average on $50 \%$ of the crops in the UK and yellow rust on average on $8 \%$ (12). Both diseases are routinely targeted with fungicides in the UK. If the occurrence or absence of an economically damaging disease infection could be forecasted then this could possibly guide fungicide usage which may have financial and environmental benefits. Here, a disease infection with a disease severity higher than $5 \%$ will be called a "damaging epidemic", for reasons explained further in the materials and methods section.

After harvest yellow rust survives on volunteer wheat, from which it is wind-dispersed to autumn sown wheat where it survives the winter. In winter, latent periods increase due to cold temperatures (35). A rapid disease increase can occur early in the spring with severe levels present by May. Yellow rust needs free moisture (high humidity, rainfall, or dew) for infection, is winddispersed, and has an optimal temperature range around 10 to $15^{\circ} \mathrm{C}(13)$. Later in the season temperatures above $23^{\circ} \mathrm{C}$ can halt yellow rust epidemics by affecting infectious lesions $(10,13$, $15,18,32)$. Powdery mildew is wind-dispersed and infects volunteers after harvest, and then infects autumn sown crops. Disease cycles can continue during the winter if temperatures are mild. In spring, as the temperature rises and humidity is high, growth

Corresponding author: F. van den Bosch

E-mail address: Frank.vandenbosch@bbsrc.ac.uk

doi:10.1094/PHYTO-98-5-0609

(C) 2008 The American Phytopathological Society increases rapidly and it infects the leaves (32). Powdery mildew germinates best at a high relative humidity ( $>95 \%)$, the temperature range for germination is around 10 to $22^{\circ} \mathrm{C}$. Disease development will decline rapidly with temperatures above $25^{\circ} \mathrm{C}$ $(15,32)$.

Despite this detailed knowledge, there are few substantial analyses of field data to determine what weather factors and in which time periods might best be used for forecasting. One method for identifying and quantifying such disease-weather relationships is 'Window Pane' (5). Window Pane is a search algorithm for identifying correlations between disease and weather variables within specified times frames. The Window Pane algorithm has been applied to a wide range of problems $(2,4,6-8)$. Although few resulting models have been used in practice, they create valuable insights in disease-weather relationships. Initially most applications used a regression analysis, but in Pietravalle et al. (25) a binary approach (using discriminant analysis) was introduced allowing conditions correlated with a damaging epidemic to be identified. In this paper we use 'Window Pane' on mildew and yellow rust with a discriminant analysis to identify key weather-disease relationships that can predict a damaging epidemic. Subsequently, we use a correlation analysis to identify which weather factors influence disease severity given that a damaging epidemic has occurred. Empirical models are formulated for both the occurrence of a damaging epidemic and for disease severity. Yellow rust on winter wheat has been analyzed previously with Window Pane by Coakley et al. (7); main factors influencing disease infection in the Pacific Northwest of the United States were winter temperature (positively correlated) and summer temperature (negatively correlated). The aim of this paper is to analyze how epidemics are correlated with weather throughout the season in the UK, how this relates to the life cycle of both diseases, and assess what weather factors can be used quantitatively for forecasting powdery mildew and yellow rust. 


\section{MATERIALS AND METHODS}

Data. Disease data for yellow rust and powdery mildew were obtained from replicated plots (which had not received fungicide treatment) in winter wheat experiments during the period from 1994 to 2000 (with the exception of 1998) at a total of 12 sites across England, Scotland, and Northern Ireland. References describing the experiments are given in Table 1. Each combination of year and site is described here as a 'year-site'. In total, 37 year-sites were available for yellow rust and 38 for powdery mildew. In each year-site, a number of observations resulting from different cultivars, were available varying from 2 to 24 . In total, 253 observations were available for yellow rust, and 324 for powdery mildew. If we were unable to classify whether a damaging epidemic occurred in an observation, due to the presence of other foliar diseases, then this observation was omitted, this only affected 8 observations. For powdery mildew, all cultivars with a National Institute of Agricultural Botany (NIAB) resistance rating (1) of four or higher, on a scale going from one (susceptible) to nine (resistant), had a damaging epidemic in $20 \%$ of the observations. The most susceptible cultivars, with a resistance rating of three or lower, had a damaging epidemic in $47 \%$ of the obser- vations. This group however consisted of only 32 observations and was too small to analyze separately. For yellow rust, 175 observations over 28 year-sites were susceptible cultivars (resistance rating five or lower) and 61 observations over 16 year-sites were resistant cultivars (resistance rating six or higher). For yellow rust, $6 \%$ of the resistant cultivars had a damaging epidemic compared with $16 \%$ of susceptible cultivars. Separating the data into two cultivar groups would have reduced the number of year-sites too much in both cultivar groups. For both diseases the analysis was only done on the full data set, but the effect of resistance was examined afterwards.

For Mycosphaerella graminicola (Fuckel) Schröter (anamorph Septoria tritici), a mean disease severity of 5\% across the upper three leaves of the canopy, which contributed most to yield (27), during grain filling has been used $(11,25)$ as an approximate economic injury level (28); which is the level of disease during yield formation that is likely to result in a yield loss with a sufficiently large economic value to justify the cost of prevention by fungicide treatment. Clearly, there are differences between Septoria tritici, powdery mildew, and yellow rust in the mechanisms by which they affect the host. However, all three are predominantly Type II pathogens, as defined by Johnson (14), which

TABLE 1. Overview of year-sites with the number of observations for each year-site and the number of observations with a damaging epidemic (shortened epidemics) per year-site, and the total number of damaging epidemics at the bottom of the table

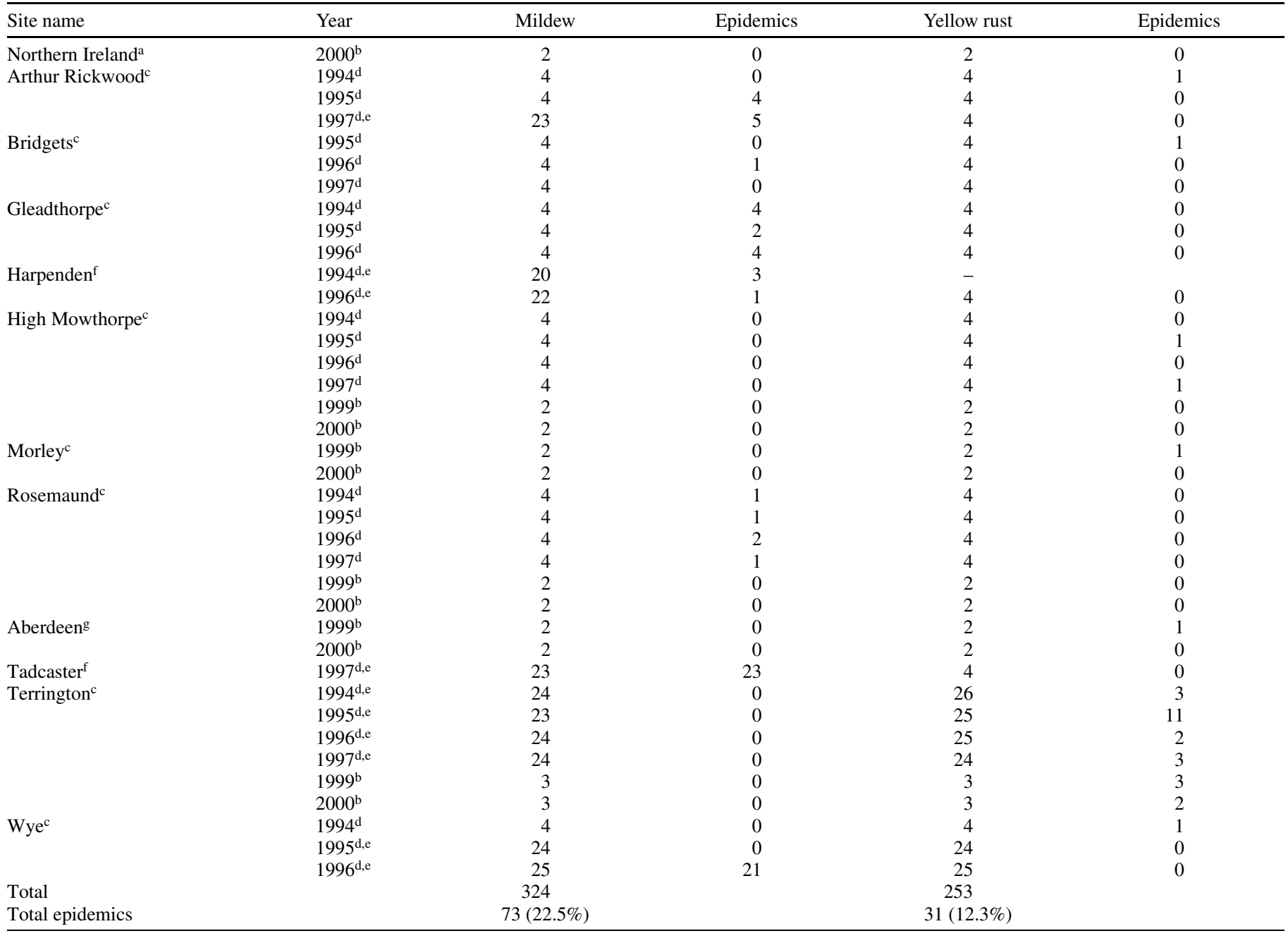

a Experiment conducted by Agricultural Research Institute of Northern Ireland.

b The experiments were obtained from and described by Milne et al. (20), from which the data were in sections entitled Validation and Data set 1.

c Experiment conducted by ADAS.

${ }^{\mathrm{d}}$ Experiments were described by Pietravalle et al. (25) where a subset of these experiments were also used previously for Window Pane analysis of Septoria tritici.

e Described in Parker et al. (23) where the Septoria tritici subset of the data was used.

${ }^{\mathrm{f}}$ Experiment conducted by Central Science Laboratory.

g Experiment conducted by Scottish Agricultural Colleges. 
cause damage which is related to the canopy area occupied by symptoms. Hence, for simplicity and to allow comparisons between the diseases, the analysis presented here adopted a severity of $5 \%$ or more, during grain filling, as defining a 'damaging epidemic'. The data consisted of visual estimates of the percentages of leaf area showing symptoms and measurements of leaf sizes for each leaf layer. We calculated disease severity ( $\mathrm{Sev}$ ) as the percentage area affected by symptoms on the top three leaf area according to

$$
\operatorname{Sev}=\frac{\sum_{i=1}^{3} \operatorname{Sev}_{i} \cdot \text { Area }_{i}}{\sum_{i=1}^{3} \text { Area }_{i}}
$$

where $S e v_{i}$ is the percentage of leaf $i$ affected by symptoms and Area $_{i}$ is the surface area of leaf layer $i$. Each observation consisted of assessments at a number of growth stages (29). For powdery mildew the average severity between GS57 (3/4 of head emerged) to GS75 (grain at medium milk) was taken as the estimate of disease severity. For yellow rust the average severity between GS50 (head visible) to GS73 (grain at early milk) was taken.

To maximize practical applicability of results for disease forecasting, daily weather data were retrieved from the Biotechnology and Biological Sciences Research Council (BBSRC) met data web for meteorological stations located within $5 \mathrm{~km}$ of each experimental site. The following daily weather data were retrieved: maximum temperature (maximum in degree Celsius), minimum temperature (minimum in degree Celsius), mean temperature (in degree Celsius, calculated as the average of maximum and minimum temperature), relative humidity (mean in \%), radiation (radiant energy from the sun in $\mathrm{MJ} \mathrm{m}^{-2}$ ), rain (in $\mathrm{mm}$ ), sunshine (hours), vapor pressure (mean in milli-bars), wind run (distance traveled by the wind in $\mathrm{km}$ ), and wind speed (mean in $\mathrm{m} \mathrm{s}^{-1}$ ). Some weather data were missing, partly due to sensor errors or because some weather items were not measured at a particular station. For vapor, rain, minimum, maximum, and mean temperature, $10 \%$ of the weather data were missing, for wind run and wind speed, $25 \%$ of the weather data were missing, and for humidity, radiation, and sunshine, $35 \%$ of the weather data were missing. Missing data were omitted from the analysis as described in the methods section.

Method. The iterative search algorithm, Window Pane, was used to identify which weather factors in which period of the growing season had the strongest relationship with the occurrence of a damaging epidemic. The algorithm has been described previously $(5,25)$ and was implemented with Genstat (24). In summary, the basis of Window Pane is an iterative search procedure by which a predefined time frame (time lag) was searched window by window as illustrated in Figure 1. Time lags (TL) varied from 300 to 40 days, and are searched in steps of 10 days. For each TL, window lengths from 120 to 40 days were searched in steps of 5 days. The lower limit of 40 days was chosen because shorter windows are more likely to be influenced by coincidental weather events and could result in spurious relationships. The upper limit of 120 was chosen to include long-term effects. All observations were aligned on growth stage 65 (flowering half complete) which is the average growth stage at which disease was observed. From growth stage 65 we counted backwards according to the TL (Fig. 1). The maximum TL of 300 days counted backwards to approximately sowing in early September which gives a full overview of the growing season. In each window for each disease observation a weather function was calculated. This weather function transformed the daily weather data in the window into a single summarizing weather variable. In each window the correlation or misclassification (described in the next section) between derived weather variables and disease observations was calculated. If a window contained days with missing weather data, the window was dropped, to ensure that each weather variable was calculated accurately in each window. In the remainder of the paper we will refer to measured weather data as weather factors. The term 'weather variable' will refer to weather factors transformed by a weather function. The weather functions used were (i) number of days in the window the weather variable was above or below a threshold, (ii) number of consecutive days above or below a threshold, (iii) the average value of the weather variable, and (iv) accumulation above or below a threshold. For each weather factor we used a range of values as thresholds based on likely values (based on median and quartiles). By repeating this process iteratively it was possible to identify the windows and weather variables that minimize the $P$ value used as measure for significance in correlation analysis, or misclassification rate in the case of a discriminant analysis.

Discriminant analysis. A binary version of the discriminant analysis was used to classify the observations into two groups. The method identified the weather variables that determined whether or not a damaging epidemic occurred (25). These disease data were classified into damaging epidemic $\{1\}$ and absence of a damaging epidemic $\{0\}$. The weather variable were similarly classified to $\{0,1\}$, but according to a threshold $x_{0}$. This threshold was estimated from the data by minimizing the misclassification rate (m), according to equation 2 , based on the weather variable.

$$
m=\frac{\min \left(\sum_{i=1}^{n}\left|\left(Y_{i}-X_{i}^{(-)}\right) \cdot w_{i}\right|, \sum_{i=1}^{n}\left|\left(Y_{i}-X_{i}^{(+)}\right) \cdot w_{i}\right|\right)}{\sum_{i=1}^{n} w_{i}}
$$

with

$$
\begin{aligned}
X_{i}^{(-)} & = \begin{cases}0 & \text { if } X_{i}>x_{0} \\
1 & \text { otherwise }\end{cases} \\
X_{i}^{(+)} & = \begin{cases}0 & \text { if } X_{i} \leq x_{0} \\
1 & \text { otherwise }\end{cases}
\end{aligned}
$$

where $Y_{i}$ is the disease severity in $\{0,1\}, X_{\mathrm{i}}$ is the weather variable for observation $i$, and $n$ is the total number of observations. All observations are weighted $\left(w_{i}\right)$ according to the number of observations in one year-site $j$ (\#obs), calculated according to equation 3 ,

$$
w_{j}=\frac{1}{\# \boldsymbol{o} \boldsymbol{b} \boldsymbol{s}_{j}}
$$

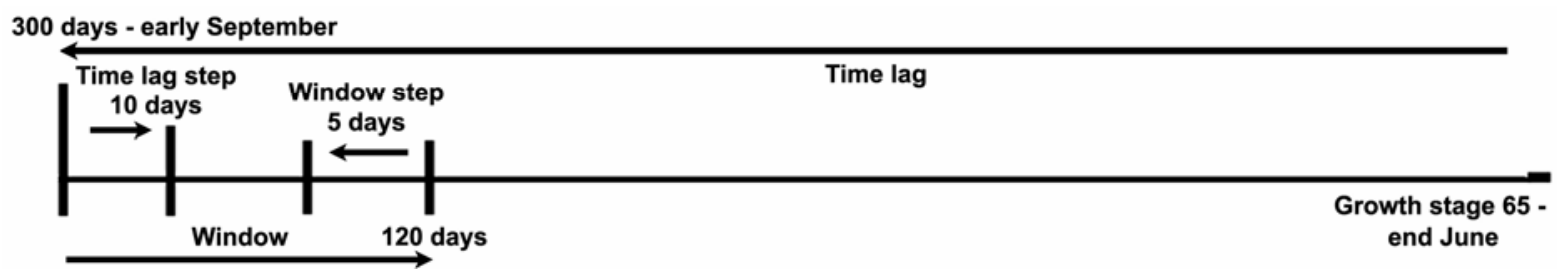

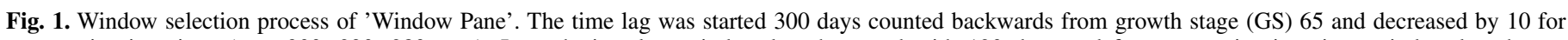

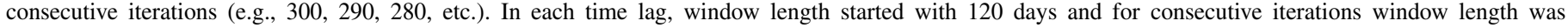

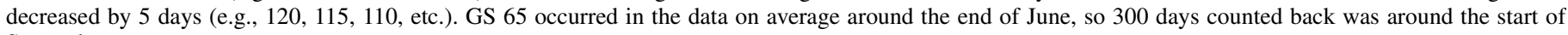
September. 
The percentage of damaging epidemics in the data for yellow rust and mildew on the total observations was relatively low, respectively, 12.3 and $22.5 \%$ percentage (Table 1 ). With this distribution of damaging epidemics, the discriminant function (equation 2) had a bias towards classifying the observations without damaging epidemic correctly (since there are more of them), resulting in more false negatives. To balance equation 2 , we multiplied the observations with an additional weight ( $c$, equation 4 and 5) in such a way that the total weight for observations with a damaging epidemic and those without a damaging epidemic were equal. Equation 2 was changed accordingly to equation 4 in which $c$ is the additional weighting factor. With this additional weight, more emphasis was put on classifying the observations with a damaging epidemic correctly:

$$
m=\frac{\min \left(\sum_{i=1}^{n}\left|\left(Y_{i}-X_{i}^{(-)}\right) \cdot w_{i} \cdot c\right|, \sum_{i=1}^{n}\left|\left(Y_{i}-X_{i}^{(+)}\right) \cdot w_{i} \cdot c\right|\right)}{\sum_{i=1}^{n} w_{i} \cdot c}
$$

with

$$
c=\frac{\sum_{i=1}^{n} w_{i}-\sum_{i=1}^{n} w_{i} \cdot Y_{i}}{\sum_{i=1}^{n} w_{i} \cdot Y_{i}}
$$

Correlation analysis. In our second analysis we looked specifically for weather factors determining the severity of a damaging epidemic given the condition that it had occurred. In this analysis we selected all observations classified as damaging epidemics (Table 1) and applied Window Pane to find the most significant time lags, time windows, and weather factors. Instead of the misclassification rate, we calculated the correlation coefficient with Genstat (24) between disease severity and weather variable and use the $P$ value as a measure of significance of how well the disease data correlated with a weather variable.

Spurious relationships. One problem with the Window Pane approach is that of apparently strong relationships occurring by pure chance (25) due to the large number of comparisons made in the analysis, which was in the order of 25,000. Such spurious relationships are difficult to identify and the problem can only be addressed rigorously with an independent data set. However, stringent selection of relationships can reduce the probability of identifying spurious relationships. We based our selection on the following criteria. The first selection criterion used was the misclassification or $P$ value. The second was the number of occasions variables based on the same weather factor identified a relationship, and the third was whether these relationships occurred in consecutive windows. If a low misclassification or $P$ value did not occur in multiple consecutive windows and in several weather functions it was unlikely to be a genuine relationship. Finally, all identified relationships should relate to what is known about the life cycle. If a mechanistic explanation can be found for the identified relationships, then they are less likely to be spurious. To select the weather variables we used a threshold minimum misclassification with weightings (M1, Tables 2 and 3) of 0.19 for powdery mildew and 0.24 for yellow rust, the secondary misclassification without weighting (M2, Tables 2 and 3) needed to be lower than 0.16 . In the correlation analysis we used a $P$ value threshold of 0.01 . The criteria were set so that the strongest $1 \%$ of relationships were selected.

Empirical models. After identifying the relationships individually the selected relationships were combined in empirical models. Relationships identified in the discriminant analysis were used to formulate empirical models for the occurrence of a damaging epidemic. The discriminant function (equation 2 and 4) only works with one variable, so to combine multiple variables into one model we used Fisher's linear discriminant function (17) or canonical variate analysis (CVA) as programmed in Genstat (24). Variables related to disease severity, given a damaging epidemic occurred, were included in empirical models using a multiple linear regression as programmed in Genstat (24) with model selection based on adjusted $R^{2}$.

TABLE 2. Results relationships between powdery mildew and weather variables identified in the misclassification and correlation analyses ${ }^{\mathrm{a}}$

\begin{tabular}{lcccc}
\hline Misclassification analysis - powdery mildew & Time lag & Window & M1 & M2 \\
\hline WindRun (number $\geq 200 \mathrm{~km}$ ) & 190 & 85 & 0.09 & 0.06 \\
WindSpeed (accumulation below $3 \mathrm{~m} \mathrm{~s}^{-1}$ ) & 190 & 75 & 0.10 & 0.16 \\
Sunshine (number $\leq 2 \mathrm{~h}$ ) & 180 & 60 & 0.17 & 0.10 \\
Radiation (accumulation below 4 MJ) & 180 & 55 & $\mathrm{R}$ & 0.09 \\
\hline Correlation analysis - powdery mildew & Time lag & Window & 0.74 & 0.69 \\
Tmin (accumulation above $12^{\circ} \mathrm{C}$ ) & 110 & 100 & 0.69 & 0.006 \\
Humid (consecutive number $\geq 95 \%$ ) & 80 & 70 & 0.009 \\
Rain (accumulation above $10 \mathrm{~mm}$ ) & 110 & 100 & 0.71 & 0.010 \\
Tmax (number $\geq 20^{\circ} \mathrm{C}$ ) & & & \\
\hline
\end{tabular}

a The first column contains the weather factor and function. Time lag and window length in the second and third columns mark the period in the season, M1 is the misclassification with additional weight $c$ (equation 4), M2 is the misclassification without additional weight, and $\mathrm{R}$ is the correlation coefficient.

TABLE 3. Results relationships between powdery mildew and weather variables identified in the misclassification analysis and correlation analysis for yellow

\begin{tabular}{|c|c|c|c|c|}
\hline Misclassification analysis - yellow rust & Time lag & Window & M1 & M2 \\
\hline Tmean (accumulation above $4^{\circ} \mathrm{C}$ ) & 130 & 115 & 0.19 & 0.12 \\
\hline Vapor (accumulation below $6 \mathrm{mb}$ ) & 140 & 80 & 0.20 & 0.15 \\
\hline Tmin (accumulation above $6^{\circ} \mathrm{C}$ ) & 90 & 80 & 0.22 & 0.12 \\
\hline Sunshine (accumulation above $4 \mathrm{~h}$ ) & 200 & 70 & 0.24 & 0.16 \\
\hline Correlation analysis - yellow rust & Time lag & Window & $\mathrm{R}$ & $P$ value \\
\hline Tmax (accumulation above $16^{\circ} \mathrm{C}$ ) & 140 & 100 & 0.85 & 0.001 \\
\hline
\end{tabular}
rust $^{\mathrm{a}}$

a The first column contains the weather factor and function. Time lag and window length mark the period in the season, M1 is the misclassification with additional weight $c, \mathrm{M} 2$ is the misclassification without additional weight, and $\mathrm{R}$ is the correlation. 


\section{RESULTS}

Mildew relationships. The relationships identified with the discriminant and correlation analyses were located in different periods of the season (early and late in the season, respectively) and different weather factors were involved. The main periods for each weather factor are illustrated in Figure 2. Table 2 shows the relationships with the lowest misclassification and $P$ value for each weather factor. Wind was found to be the main weather factor influencing the probability of a damaging epidemic followed by sunshine and radiation. Temperature was the main weather factor influencing disease severity given a damaging epidemic.

Yellow rust relationships. For yellow rust, weather conditions associated with a damaging epidemic were similar to the conditions that contributed to a high disease severity (Fig. 3). The main weather factors are illustrated in Figure 3 and Table 3 shows the relationships with the lowest misclassification and $P$ value for each weather factor. Temperature was the most important weather factor influencing both the probability of damaging epidemics and disease severity. As a second variable, vapor pressure deficit was identified as an important weather factor influencing the occurrence of a damaging epidemic.

Mildew models. The best model describing the relationship between weather and the development of a damaging epidemic for powdery mildew was formed with wind run (Fig. 4); adding a

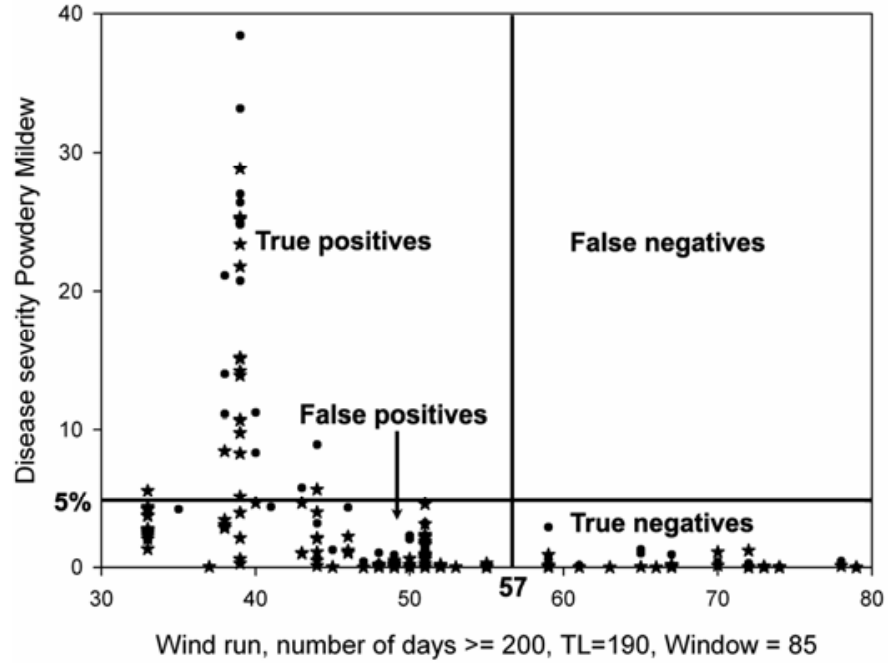

Fig. 4. Number of days with wind run $\geq 200 \mathrm{~km}$ (in an 85 day window with a time lag of 180 days) plotted against the disease severity of powdery mildew with true and false positives and negatives indicated. A damaging epidemic was predicted if more than 57 days were above $200 \mathrm{~km}$ a day. Observations from resistant and susceptible cultivars are marked with a star and dot, respectively.

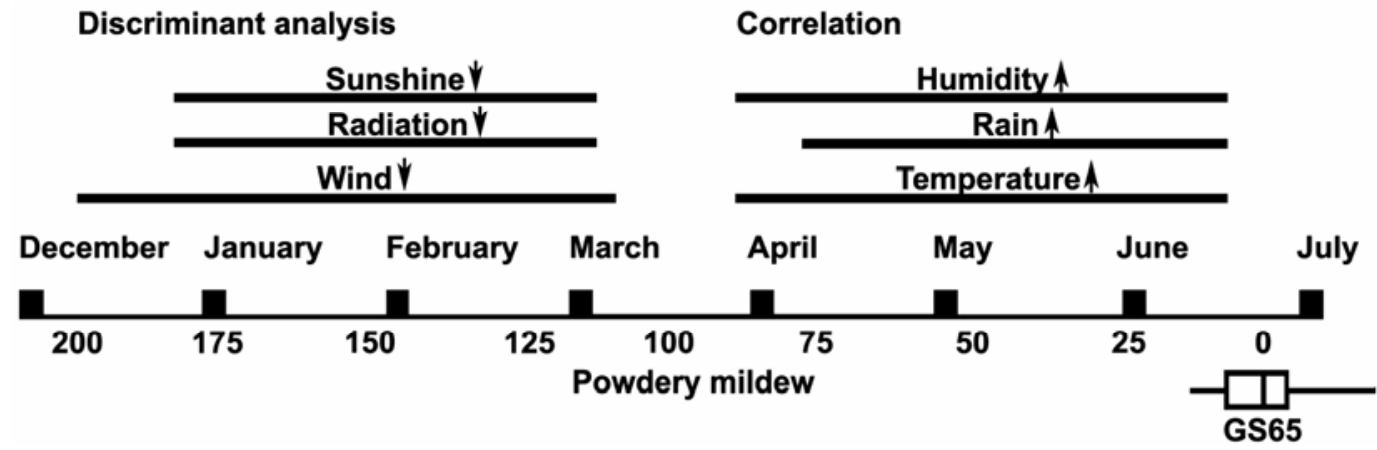

Fig. 2. The main influential periods for powdery mildew during which weather was strongly related to subsequent disease are illustrated. The time line indicates days counted backwards from growth stage (GS) 65. The box plot is the spread in GS 65 dates. The arrows indicate the effect of each variable, an arrow down means, for example, less wind is related to a larger probability of a damaging epidemic for the discriminant analysis (left) and more rain related to a higher disease severity in the correlation analysis (right).

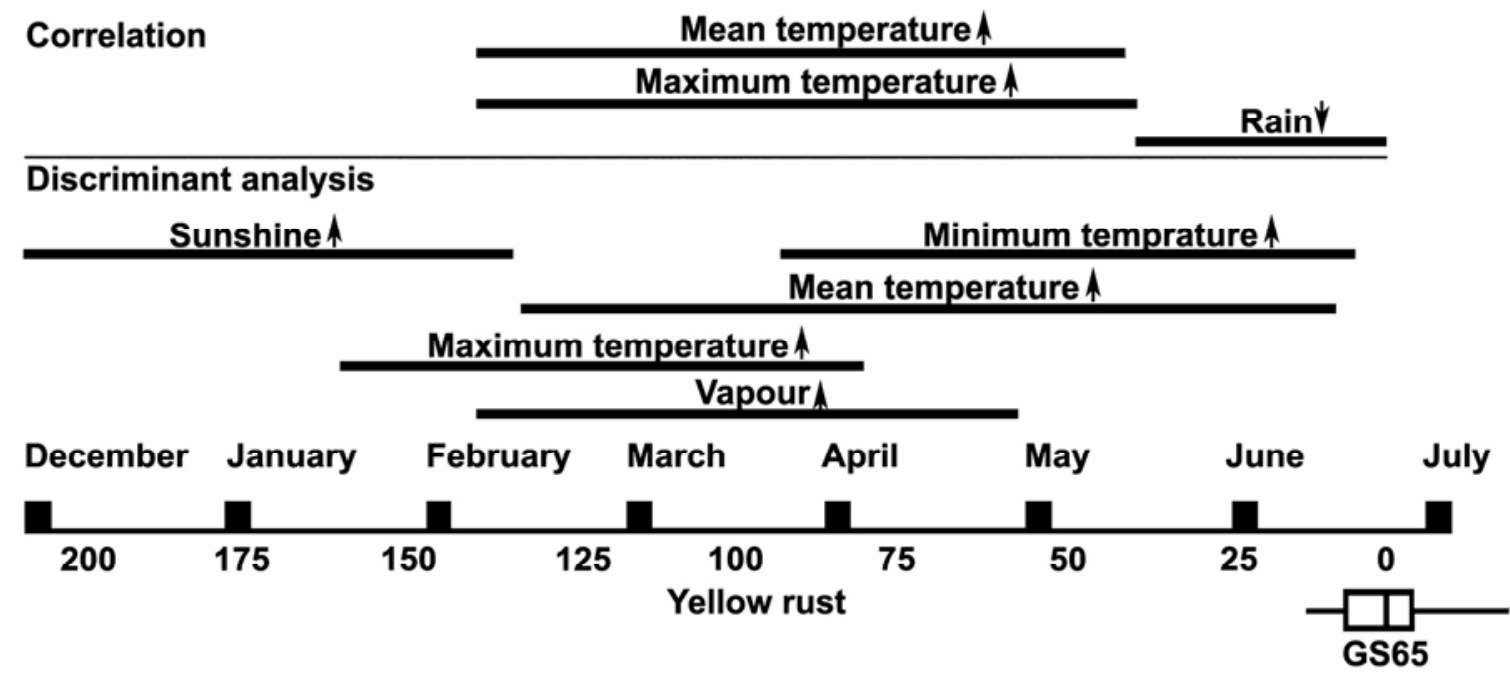

Fig. 3. Illustration of main influential periods for yellow rust. The time line indicates days counted backwards from growth stage (GS) 65 . The box plot is the spread in GS 65 dates. The arrows indicates the effect of the variable, a higher temperature is related to a larger probability of a damaging epidemic for the discriminant analysis (lower half), and is related to higher disease severity in the correlation analysis (upper half). 
second variable did not decrease the misclassification rate. A model with similar accuracy could have been built with wind speed, but wind run had a marginally lower misclassification. Alternative models consisted of sunshine or radiation; adding a second variable to these models did not lower the misclassification. The best model describing disease severity given a damaging epidemic combined rain, maximum temperature, and humidity with an $R^{2}$ of $82.5 \%$, whereas excluding humidity reduced the $R^{2}$ to $77.3 \%$ (Table 4 ).

Yellow rust models. The best model describing the relationship between weather and the development of a damaging epidemic for yellow rust combined mean temperature and vapor pressure. The model had few false negatives, but many false positives. Vapor pressure is often unavailable from weather stations, but an alternative model including only mean temperature (Fig. 5) showed higher false negative misclassification and higher false positives (Table 5). The best model describing disease severity given a damaging epidemic occurred for yellow rust consisted of maximum temperature and rain, with an $R^{2}$ of $86.4 \%$. But the relationship with rain can be questioned (see discussion). An alternative model including only maximum temperature, had an $R^{2}$ of $70.2 \%$ (Table 5 ).

\section{DISCUSSION}

Weather variables related to damaging epidemics and disease severity given a damaging epidemic occurred have been identified. The misclassification and $R^{2}$ values cited are for the data with which the models were derived and are therefore potentially optimistic. To assess the accuracy of the models a validation on independent data is needed. However a subjective assessment of the models can be made by comparing the identified relationships to what is known about the epidemiology and the life cycle of powdery mildew and yellow rust. We then compare our results with other published Window Pane results and discuss how the results might be used for forecasting.

Powdery mildew. Wind run during the early part of the season was the main weather factor related to damaging epidemics of mildew, a small wind run increased probability on a damaging epidemic. Still conditions create a humid environment, and it is known that high humidity favors the development of powdery mildew infection $(15,32)$. A similar result was found by Friedrich (9) with a deterministic model simulating the infection cycle to forecast the infection probability of powdery mildew; the conclusion was that more wind had a negative effect on the probability of infection.

Wind also plays an important role in the dispersal of powdery mildew $(15,32)$, affecting the abundance of initial inoculum if there are few initial sources. However, in our analysis we did not find any positive correlation between wind and the probability of a damaging epidemic. This suggests the effect of wind on humidity is stronger than the effect of wind on dispersal. Low wind runs may still be sufficient to move initial inoculum between fields. No relationship was found with vapor pressure, also commonly

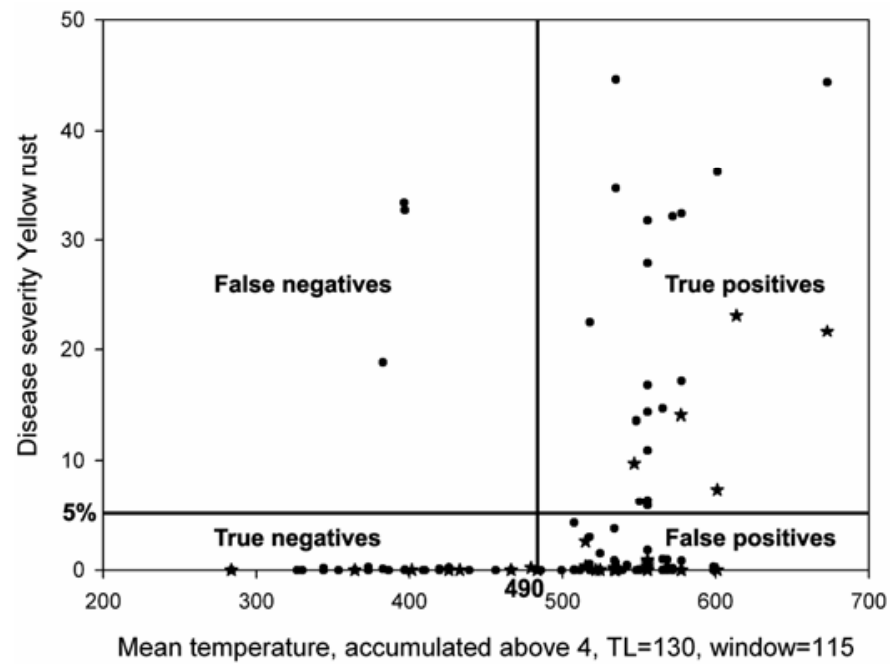

Fig. 5. Mean temperature accumulated above $4^{\circ} \mathrm{C}$ (in a 115 day time window with a time lag of 130 days) plotted against the disease severity of yellow rust with true and false positives and negatives indicated. A damaging epidemic is predicted if more than $490^{\circ} \mathrm{C}$ days was accumulated in the 130 to 115 window. Observations from resistant and susceptible cultivars are marked with a star and dot, respectively.

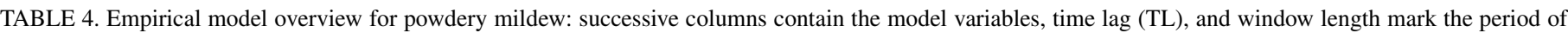

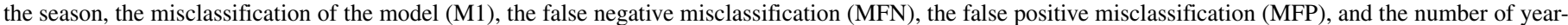
sites in the model (YS) ${ }^{\mathrm{a}}$

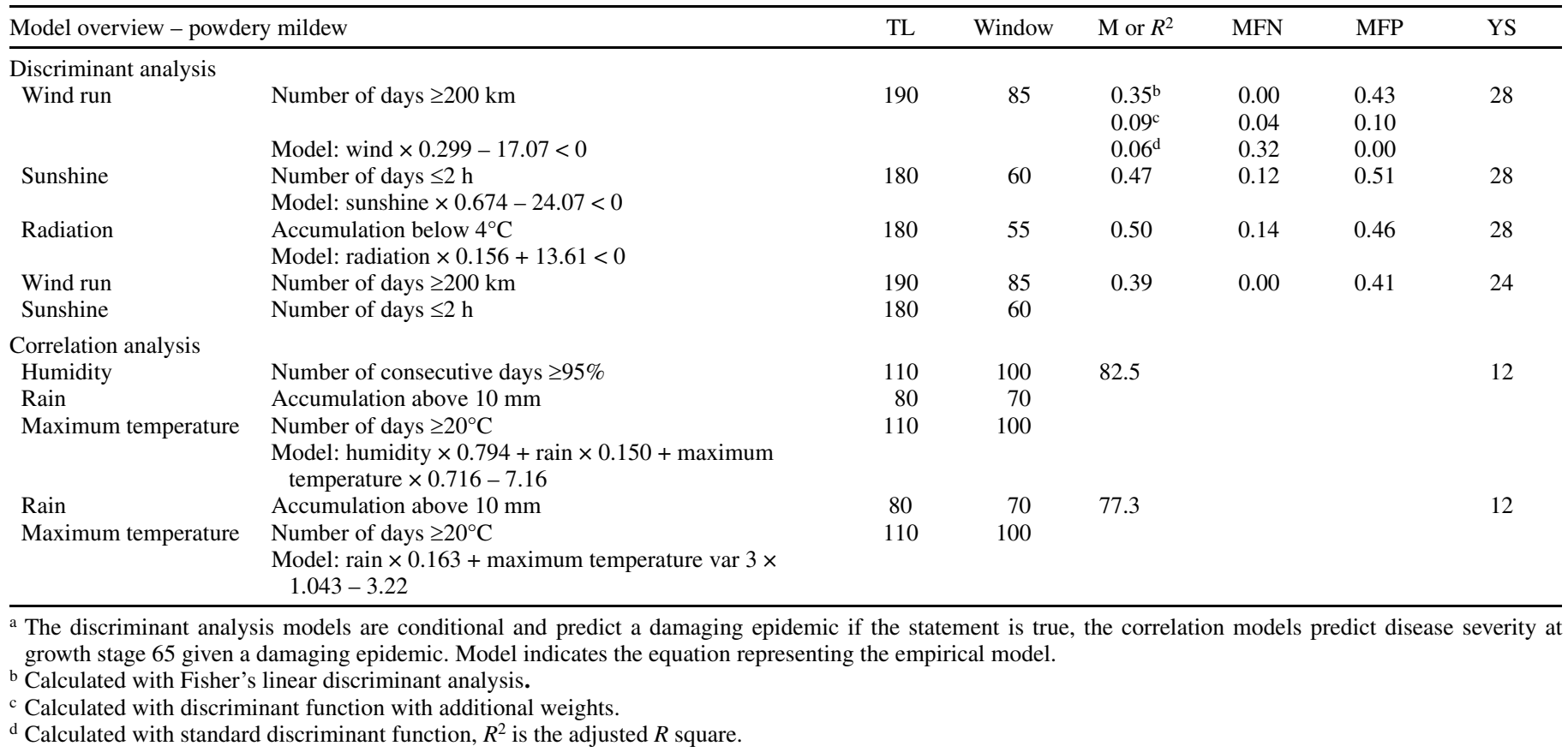


associated with leaf wetness (21). Friedrich (9) found that both a high and a low vapor pressure decreased the chance on disease infection, which would have made it difficult to find such a relationship with our analysis. High relative humidity in the range of 95 to $100 \%$ favors disease development $(15,32)$. The relationship found here between disease severity and the number of consecutive days above $95 \%$ relative humidity corresponds with this. However, relationships with humidity are often weak because average daily humidity measured in a meteorological station only weakly represents what is actually happening in a crop canopy. Most stages of the mildew infection proceed at low light intensity (32), and sunshine dries out the plant and decreases humidity. The relationship with sunshine found here corresponds with this. Low radiation and sunshine hours were both in a similar time window associated with a higher probability of a damaging epidemic, probably because radiation and sunshine are highly correlated and have the same influence on the life cycle.

The key relationship found with disease severity, given a damaging epidemic occurred, was accumulated minimum temperature above $12^{\circ} \mathrm{C}$ and the number of days with maximum temperature exceeding $20^{\circ} \mathrm{C}$, which is the equivalent of a mean temperature of $16^{\circ} \mathrm{C}$. These are in broad agreement with previous measurements of the optimal temperature range for mildew between 15 and $22^{\circ} \mathrm{C}(15,32)$. A higher temperature was correlated with a higher disease severity, so both relationships suggests that in the UK in April, May, and early June, temperature is a limiting factor in mildew development. We did not find a relationship with a high temperature limiting epidemic development, probably because temperatures were not high enough during the period analyzed to inhibit growth. Another relationship found with disease severity, given a damaging epidemic occurred, was rain. Rainfall has been reported to have opposing effects. Heavy rain is often followed by high relative humidity, creating good conditions for powdery mildew $(15,32)$, but rain can also wash away spores (19). Our analysis suggests that the effect of rain on humidity predominates under UK conditions.

Yellow rust. Temperature was the most influential factor for both the occurrence of a damaging epidemic and disease severity given a damaging epidemic occurred. The temperature range for yellow rust is optimal between 10 and $15^{\circ} \mathrm{C}$ with limits near 0 and $21^{\circ} \mathrm{C}$; temperatures higher than $23^{\circ} \mathrm{C}$ will slow down an epidemic $(13,32)$. The relationships found corresponded with this temperature range. By analyzing epidemic growth rate, Papastamati et al. (22) also found that temperature was the most important variable for the progress of yellow rust. Christensen et al. (3) found that the temperature in January and February is positively correlated with yellow rust severity. In Gladders et al. (10) a high winter temperature, associated with overwintering, was identified as the most important factor for yellow rust infections later in the season. Coakley et al. (6) found a similar positive correlation between the average temperature and disease severity in January, followed by a negative correlation with the number of days above $25^{\circ} \mathrm{C}$ in May and June. In our results a higher temperature was associated with a higher likelihood of damaging epidemics and is associated with subsequent higher disease severity, suggesting that temperature is a limiting factor correspondent with the January period found by Coakley et al. (6) and Christensen et al. (3). We did not find a negative relationship between high temperatures and yellow rust, probably because the temperature in England seldom exceeded $25^{\circ} \mathrm{C}$ in the period we analyzed. Yellow rust epidemics are nonetheless sometimes halted by periods of hot weather but mainly after growth stage 65 (flowering half complete).

A relationship was found between accumulated vapor pressure below six milli-bars and a lower risk of damaging epidemics, (i.e., higher vapor pressure increased disease). Vapor pressure influences leaf wetness which, considering the dependency of yellow rust on free moisture, would explain this relationship. Another requirement for the development of yellow rust is the availability of short periods with free moisture, which can be either high humidity, rainfall, or dew $(15,32)$. We did not find a relationship that is in line with this, suggesting the availability of free moisture is not a limiting factor. This may be because UK weather is characterized by periods of anti-cyclonic weather, during which dew commonly forms overnight, alternating with frontal systems carrying rain. In the misclassification analysis we found a positive relationship with sunshine. Light quantity, related to sunshine, has been shown to positively influence infection efficiency $(18,30,31)$.

Model accuracy. For both powdery mildew and yellow rust the models identify favorable circumstances in which a damaging epidemic may occur. But both models resulted in many false positives, this means a damaging epidemic did not occur despite the model indicating favorable conditions. In these cases other factors are presumably involved, such as the absence of initial inoculum, disease resistance, or unfavorable weather events not captured in the models. Survey data suggests one important contrast; powdery mildew occurs on average on $50 \%$ of the crops in the UK whereas yellow rust only occurs on average on $8 \%$ (12). The high mobility of mildew conidia and the high incidence of infected crops make false positives due to lack of initial inoculum unlikely. In contrast, the lower mobility of yellow rust spores and the low incidence of affected fields to act as sources of inoculum, may explain some of the false positives for rust. For yellow rust there was a noticeable effect of cultivar resistance (Fig. 5). The number of damaging epidemics was greater for susceptible

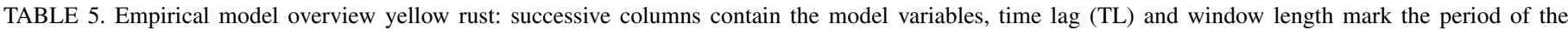

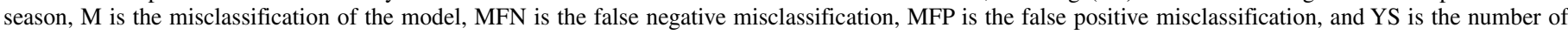
year-sites in the model $^{\mathrm{a}}$

\begin{tabular}{|c|c|c|c|c|c|c|c|}
\hline \multicolumn{2}{|c|}{ Model overview - yellow rust } & \multirow[t]{2}{*}{$\mathrm{TL}$} & \multirow[t]{2}{*}{ Window } & \multirow[t]{2}{*}{ M or $R^{2}$} & \multirow[t]{2}{*}{ MFN } & \multirow[t]{2}{*}{ MFP } & \multirow[t]{2}{*}{ YS } \\
\hline Discriminant analysis & & & & & & & \\
\hline Vapor & Accumulation below 6 mbar & 140 & 100 & 0.47 & 0.02 & 0.43 & 24 \\
\hline Mean temperature & $\begin{array}{l}\text { Accumulation above } 4^{\circ} \mathrm{C} \\
\text { Model: vapor } \times 0.0383+\text { mean temperature } \times-0.00214-19.2>0\end{array}$ & 130 & 115 & & & & \\
\hline Mean temperature & $\begin{array}{l}\text { Accumulation above } 4^{\circ} \mathrm{C} \\
\text { Model: mean temperature } \times 0.0385-19.08>0\end{array}$ & 130 & 115 & 0.50 & 0.07 & 0.56 & 25 \\
\hline \multicolumn{8}{|l|}{ Correlation analysis } \\
\hline Maximum temperature & Accumulation above $16^{\circ} \mathrm{C}$ & 140 & 100 & 86.4 & & & 11 \\
\hline Rain & $\begin{array}{l}\text { Number of days } \geq 8 \mathrm{~mm} \\
\text { Model: maximum temperature } \times 0.5+\text { rain } \times-4.08+2.54\end{array}$ & 40 & 40 & & & & \\
\hline Maximum temperature & $\begin{array}{l}\text { Accumulation above } 16^{\circ} \mathrm{C} \\
\text { Model: maximum temperature } \times 0.777-5.73\end{array}$ & 140 & 100 & 70.2 & & & 12 \\
\hline
\end{tabular}

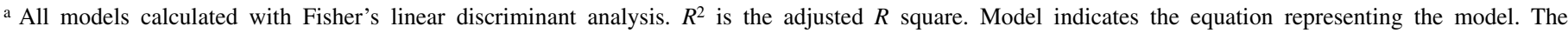
discriminant analysis models are conditional and predict a damaging epidemic if the statement is true, the correlation models predict disease severity at growth stage 65 given a damaging epidemic. 
Septoria tritici

(Pietravalle et al. (25))

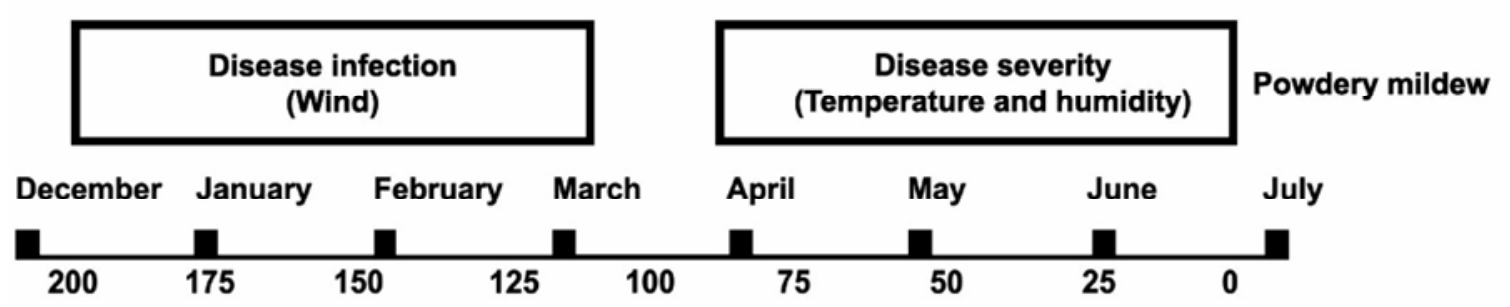

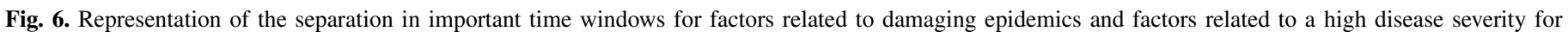

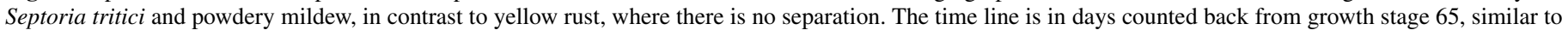
Figures 2 and 3.

cultivars and the severity of those epidemics was higher. For yellow rust, a damaging epidemic on susceptible cultivars occurred in circumstances identified as unfavorable (false negative). For powdery mildew there was a less noticeable effect of cultivar resistance (Fig. 4).

Comparisons between diseases. For powdery mildew a separation was found, both in weather factors and in period of the season, between the weather variables related to occurrence of a damaging epidemic and weather variables related to disease severity given a damaging epidemic. There was no such separation for yellow rust (Fig. 6). Window Pane analysis of Septoria tritici (25) produced a similar pattern of results to those seen here for powdery mildew, in that it was possible to distinguish an early period and a later period (Fig. 6). These findings may reflect fundamental differences in epidemiology, but our analysis did not suggest an obvious mechanistic explanation. Yellow rust, if it occurs, is more likely to reach a high severity than powdery mildew. If the initial conditions for a damaging epidemic have been met, then conditions favorable for a high disease severity, both temperature related, are also likely to be met under UK conditions. For powdery mildew, the initial inoculum necessary for occurrence of a damaging epidemic and conditions favorable for a high disease severity are very different both in time and weather factor, and have to be met separately.

Disease prediction. If a disease forecast is to be used to guide fungicide treatment decisions, a prediction is needed before the first spray. For powdery mildew the relationships identified with the discriminant analysis, and models based on them, are suitable for this. For yellow rust, early prediction is more difficult; the period in which most of the strong, temperature, relationships occur continue until after the growth stage when the first spray is usually applied. Maximum temperature could be used for an early indication, but it is one of the weaker relationships. Early field observations of yellow rust have been shown to have predictive value (33), so a forecast system combining weather and disease observations may be sufficiently accurate to be useful.

False negatives are potentially more damaging in guiding fungicide sprays than false positives, for both yellow rust and powdery mildew the false negatives are low which suits such prediction. A different trade-off between false negatives and falsepositives may be preferred for different objectives, such as maximizing economic returns or minimize disease risk, and also by alternative beneficiaries (26). The trade-off can be altered by adjusting the model, as shown in Table 4 for the wind run model. A full analysis of the trade-off could be done using the receiver operating curve methodology as described by $(16,34)$.
Window Pane. The advantage of Window Pane is that with the iterative search, quantitative relationships between weather and disease can be located in a specific period. A disadvantage of Window Pane is that the iterative search generates a large amount of potential relationships and creates a selection problem. We therefore used qualitative selection criteria which makes the selection of relationships difficult to fully automate, complicating a cross validation which could be used as a tool to identify spurious relationships. The choice of weather functions may seem arbitrary, and although in principle it is easy to use nonlinear functions with several parameters even for a single weather variable, it is difficult to see how a systematic search can be built with them. For example, the relationships with temperature here are not closely related to those in mechanistic models (21). However, the interplay of automated search and biologically informed choices provides an illuminating analysis of our data set, generating worthwhile hypotheses about predictive relationships of practical use, with unexpected features, in particular, the importance of wind in the early season in mildew.

\section{ACKNOWLEDGMENTS}

This project has been funded by the Department for Environment Food and Rural Affairs (DEFRA), United Kingdom. Rothamsted Research receives support from Biotechnology and Biological Sciences Research Council (BBSRC) of the United Kingdom. Weather data used are Crown copyright data supplied by the Met Office.

\section{LITERATURE CITED}

1. Anonymous. 1994-2000. Cereal variety handbook: NIAB recommended list of cereals. Edited by NIAB. National Institute of Agricultural Botany, Camebridge, UK.

2. Calvero, S. B., Coakley, S. M., and Teng, P. S. 1996. Development of empirical forecasting models for rice blast based on weather factors. Plant Pathol. 45:667-678.

3. Christensen, K., Jorgensen, L. N., and Secher, B. J. M. 1993. Development of a yellow rust model based on historical data. Pages 71-78 in: Proceeding of the 10th Danish plant protection conference. Plantevaernscentret, Lyngby, Denmark.

4. Chuang, T. Y., and Jeger, M. J. 1987. Predicting the rate of development of Black Sigatoka (Mycosphaerella fijiensis var. difformis) disease in southern Taiwan. Phytopathology 77:1542-1547.

5. Coakley, S. M., and Line, R. F. 1982. Prediction of stripe rust epidemics on winter wheat using statistical models. Phytopathology 72:1006.

6. Coakley, S. M., Line, R. F., and McDaniel, L. R. 1988. Predicting stripe rust severity on winter wheat using an improved method for analyzing meteorological and rust data. Phytopathology 78:543-550.

7. Coakley, S. M., McDaniel, L. R., and Shaner, G. 1985. Model for predict- 
ing severity of septoria tritici blotch on winter wheat. Phytopathology 75:1245-1251.

8. Francl, L. J., Madden, L. V., Rowe, R. C., and Riedel, R. M. 1990. Correlation of growing season environmental variables and the effect of early dying on potato yield. Phytopathology 80:425-432.

9. Friedrich, S. 1995. Modeling infection probability of powdery mildew in winter wheat by meteorological input variables. Zeitschrift Fur Pflanzenkrankheiten Und Pflanzenschutz-J. Plant Dis. Prot. 102:354-365.

10. Gladders, P., Langton, S. D., Barrie, I. A., Taylor, M. C., and Paveley, N. D. 2007. The importance of weather and agronomic factors for the overwinter survival of yellow rust (Puccinia striiformis) and subsequent disease risk in commercial wheat crops in England. Ann. Appl. Biol. 150:371-382

11. Gladders, P., Paveley, N. D., Barrie, I. A., Hardwick, N. V., Hims, M. J., Langton, S., and Taylor, M. C. 2001. Agronomic and meteorological factors affecting the severity of leaf blotch caused by Mycosphaerella graminicola in commercial wheat crops in England. Ann. Appl. Biol. 138:301-311.

12. Hardwick, N. V., Jones, D. R., and Slough, J. E. 2001. Factors affecting diseases of winter wheat in England and Wales, 1989-98. Plant Pathol. 50:453-462.

13. Hoggs, W. H., Houman, C. E., Mallik, A. K., and Zadoks, J. C. 1969. Meteorological factors affecting the epidemiology of wheat rusts. World Meteorological Organization, Geneva, Switzerland.

14. Johnson, K. B. 1987. Defoliation, disease, and growth: A reply. Phytopathology 77:1495-1497.

15. Jones, D. G., and Clifford, B. C. 1983. Cereal Disease. Their Pathology and Control. 2nd ed. John Wiley \& Sons, New York.

16. Madden, L. V. 2006. Botanical epidemiology: Some key advances and its continuing role in disease management. Eur. J. Plant Pathol. 115:3-23.

17. Mardia, K. V., Kent, J. T., and Bibby, J. M. 1979. Multivariate Analysis. Academic Press, London.

18. McGregor, A. J., and Manners, J. G. 1985. The effect of temperature and light intensity on growth and sporulation of puccinia striiformis on wheat. Plant Pathol. 34:263-271.

19. Merchan, V. M., and Kranz, J. 1986. The effect of rain on the development of wheat powdery mildew (Erysiphe-graminis Dc f. sp. tritici). Zeitschrift Fur Pflanzenkrankheiten Und Pflanzenschutz-J. Plant Dis. Prot. 93:262-270.

20. Milne, A., Paveley, N., Audsley, E., and Livermore, P. 2003. A wheat canopy model for use in disease management decision support systems. Ann. Appl. Biol. 143:265-274.

21. Papastamati, K., McCartney, H. A., and van den Bosch, F. 2004. Modelling leaf wetness duration during the rosette stage of oilseed rape. Agric. For. Meteorol. 123:69-78.
22. Papastamati, K., and Van den Bosch, F. 2006. The sensitivity of the epidemic growth rate to weather variables, with application to yellow rust on wheat. Phytopathology 94:202-210.

23. Parker, S. R., Welham, S., Paveley, N. D., Foulkes, J., and Scott, R. K. 2004. Tolerance of septoria leaf blotch in winter wheat. Plant Pathol. 53:1-10.

24. Payne, R. W., Baird, D. B., Cherry, M., Gilmour, A. R., Harding, S. A., Kane, A. F., Lane, P. W., Murray, D. A., Soutar, D. M., Thompson, R., Todd, A. D., Wilson, G., Tunnicliffe, W. R., and Welham, S. J. 2004. Genstat Release 8 Reference Manual. Vol. 3. VSN International Ltd., Oxford.

25. Pietravalle, S., Shaw, M. W., Parker, S. R., and van den Bosch, F. 2003. Modeling of relationships between weather and Septoria tritici epidemics on winter wheat: A critical approach. Phytopathology 93:13291339.

26. Royle, D. J., and Shaw, M. W. 1988. The costs and benefits of disease forecasting in relation to its adoption in farming practice. In: Control of Plant Disease: Costs and Benefits. B. C. Clifford and E. Lester, eds. Blackwell Scientific Publications, Oxford.

27. Seck, M., Roelfs, A. P., and Teng, P. S. 1991. Influence of leaf position on yield loss caused by wheat leaf rust in single tillers. Crop Prot. 10:222228.

28. Stern, V. M., Smith, R. F., van den Bosch, R., and Hagen, K. S. 1959. The integrated control concept. Hilgardia 29:81-101.

29. Tottman, D. R. 1987. The decimal code for the growth stages of cereals, with illustrations. Ann. Appl. Biol. 110:441-454.

30. Vallavieille-Pope, C., Huber, L., Leconte, M., and Bethenod, O. 2002. Preinoculation effects light quantity on infection efficiency of Puccinia striiformis and P. triticina on wheat seedlings. Epidemiology 92:13081314.

31. Vallavieille-Pope, C., Huber, L., Leconte, M., and Goyeau, H. 1994. Comparative effects of temperature and interrupted wet periods on germination, penetration, and infection of Puccinia recondita f. sp. tritici and $P$. striiformis urediniospores on wheat seedlings. Phytopathology 85:409-415.

32. Wiese, M. V. 1987. Compendium of Wheat Diseases. 2nd ed. American Phytopathological Society, St. Paul, MN.

33. Young, C. S., Paveley, N. D., Vaughan, T. B., Thomas, J. M., and Lockley, K. D. 2003. Predicting epidemics of yellow rust (Puccinia striiformis) on the upper canopy of wheat from disease observations on lower leaves. Plant Pathol. 52:338-349.

34. Yuen, J. E., and Hughes, G. 2002. Bayesian analysis of plant disease prediction. Plant Pathol. 51:407-412.

35. Zadoks, J. C. 1961. Yellow rust on wheat. Studies in epidemiology and physiologic specialization. Tijdschrift Plantenziekten 67:69-256. 